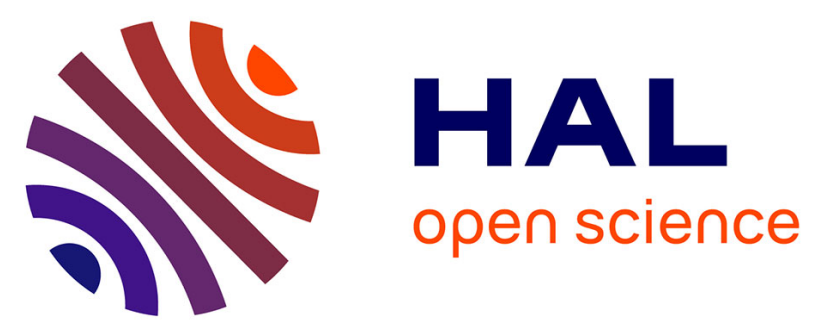

\title{
Microencapsulation of benzalkonium chloride enhanced its antibacterial and antibiofilm activity against Listeria monocytogenes and Escherichia coli
}

\author{
Simon Khelissa, Adem Gharsallaoui, Alexandre Fadel, Alexandre Barras, \\ Charafeddine Jama, Fouzia Jbilou, Nour-Eddine Chihib
}

\section{To cite this version:}

Simon Khelissa, Adem Gharsallaoui, Alexandre Fadel, Alexandre Barras, Charafeddine Jama, et al.. Microencapsulation of benzalkonium chloride enhanced its antibacterial and antibiofilm activity against Listeria monocytogenes and Escherichia coli. Journal of Applied Microbiology, 2021, 131, pp 1136-1146. 10.1111/jam.15010 . hal-03137614

\author{
HAL Id: hal-03137614 \\ https://hal.science/hal-03137614
}

Submitted on 10 Feb 2021

HAL is a multi-disciplinary open access archive for the deposit and dissemination of scientific research documents, whether they are published or not. The documents may come from teaching and research institutions in France or abroad, or from public or private research centers.
L'archive ouverte pluridisciplinaire HAL, est destinée au dépôt et à la diffusion de documents scientifiques de niveau recherche, publiés ou non, émanant des établissements d'enseignement et de recherche français ou étrangers, des laboratoires publics ou privés. 
1 Microencapsulation of benzalkonium chloride enhanced its antibacterial

\section{and antibiofilm activity against Listeria monocytogenes and Escherichia coli}

Simon Khelissa ${ }^{1}$, Adem Gharsallaoui ${ }^{2}$, Alexandre Fadel $^{3}$, Alexandre Barras ${ }^{4}$, Charafeddine Jama ${ }^{1}$, Fouzia Jbilou ${ }^{5}$, Nour-Eddine Chihib ${ }^{1 *}$

${ }^{1}$ Univ Lille, CNRS, INRAE, Centrale Lille, UMR 8207 - UMET - Unité Matériaux et Transformations, F-59000 Lille, France

${ }^{2}$ Univ Lyon, Université Claude Bernard Lyon 1, CNRS, LAGEPP UMR 5007, 43 bd 11 Novembre 1918, 69622 Villeurbanne, France

${ }^{3}$ Univ Lille, CNRS, INRAE, ENSCL, Université d'Artois, FR 2638 - IMEC -Institut MichelEugène Chevreul, F-59000 Lille, France

${ }^{4}$ Univ. Lille, CNRS, Centrale Lille Univ. Polytechnique Hauts-de-France, UMR 8520-IEMN, F-59000 Lille, France

${ }^{5}$ Former student of Univ Lille

Running headline: Antibiofilm action of microencapsulated BAC

\section{*Corresponding author: email: nour-eddine.chihib@univ-lille.fr}


25

26

27

\section{Abstract}

\section{Aims}

In this study, benzalkonium chloride (BAC) microcapsules were developed for surface disinfection purpose and were evaluated against Listeria monocytogenes and Escherichia coli biofilms.

\section{Methods and Results}

Microcapsules were prepared with two different strategies: uncomplexed BAC-microcapsules (UBM), containing BAC and maltodextrins and complexed BAC-microcapsules (CBM) containing BAC complexed by pectin and maltodextrins. The minimum inhibitory concentrations (MICs) of free and microencapsulated BAC was investigated against two food pathogens: L. monocytogenes and E. coli. The antibiofilm activities of UBM and CBM against L. monocytogenes and E. coli biofilms formed on stainless steel at $37^{\circ} \mathrm{C}$ were evaluated and compared to BAC used under its free form. MICs of encapsulated BAC were up to 4-fold lower than those of free BAC. The UBM and CBM showed higher antibiofilm effect when compared to the free BAC.

\section{Conclusions}

Overall, results demonstrated that microencapsulation enhanced the antibacterial activity of BAC against $L$. monocytogenes and $E$. coli biofilms.

\section{Significance and Impact of the Study}

The application of such BAC microcapsule-based delivery systems can improve surface disinfection procedures and reduce the required BAC concentrations and the related cytotoxicity of this antimicrobial compound.

Keywords: Benzalkonium chloride, Listeria monocytogenes, Escherichia coli, microencapsulation, antibiofilm activity 


\section{Introduction}

Spray-drying microencapsulation is the most common method for turning a fluid solution into dry particles due to its economical and easy operation (Abrahão et al. 2019). Spray-drying is commonly used for microencapsulation in food and pharmaceutical industries. Applying spraydrying for the encapsulation may impose stresses on the encapsulated active molecules through exposure to high temperature, shearing, and dehydration. However, good control of the operating parameters during the drying process makes it possible to reduce the residence time of the capsules in the drying chamber and to protect the biological activity. Our previous researches have proved the effectiveness of spray-drying microencapsulation of different active compounds with pectin (Ben Amara et al. 2016, 2017).

Quaternary ammonium compounds (QACs) are the major class of cationic surfactants used as disinfectants in domestic, industrial, and medical applications (Zhang et al. 2015). Their structure consists of a positively charged nitrogen atom and four covalently bonded alkyl groups. There is at least one hydrophobic hydrocarbon chain in these four alkyl groups, and other alkyl groups are mostly short-chain moieties such as methyl or benzyl groups. The annual worldwide consumption of QACs was reported as 500,000 tons in 2004 (Chen et al. 2018), the production of QACs per year exceeds 344,000 tons in US (Phan 2019), and it is expected to continuously increase in the future. QACs are generally considered to be biodegradable in an activated sludge system. However, this degradation varies depending on the QAC concentration, chemical structure, complexation with anionic surfactants, and microbial acclimation (Zhang et al. 2015). Benzalkonium chloride (BAC) is a broad-spectrum antimicrobial widely used to disinfect environmental surfaces in clinical and food industrial settings (Kim et al. 2018). BAC has a benzyl group, two methyl groups and an alkyl chain (C12-C18). BAC of various carbo chain lengths have diverse applications ranging from surface disinfection in hospitals, food production, agriculture or dairy industry, to their use in eye drops 
and hair shampoos (Kampf 2018; Mulder et al. 2018). On the other hand, BAC can also cause genotoxic effects in mammalian and plant cells at environmentally relevant concentrations (Ferk et al. 2007). The extensive use of QACs in domestic and industrial applications has outcompeted its biodegradation in the environment, which results in its enrichment in wastewaters and aquatic environment. When the concentration of some QACs excesses certain level in the environment, they become ecotoxic (Elersek et al. 2018). Therefore, there is a growing concern on the presence of QACs in the environment, and the reduction of usage of QACs should be a good study direction.

Pectin is a water soluble polysaccharide widely used in food manufacturing for its thickening and gelling properties. Native pectins are high methoxyl pectin in which the majority of carboxylic acid group are esterified by methanol and consequently non ionizable: therefore, in the present work, LM pectin having a higher proportion of free ionized carboxylic acid groups was considered in order to favor electrostatic interactions with positively charged BAC.

In this study, we use an electrostatic anchoring strategy to fix BAC inside microcapsules containing pectin. The purpose is then to evaluate the effects of pectin complexation and spraydrying microencapsulation on the antibiofilm activity of BAC. The cytotoxicity of both free and microencapsulated BAC was evaluated. The overall goal was to improve the effectiveness of this disinfectant through its microencapsulation while reducing the used amounts and resulting cytotoxicity.

\section{Materials and methods}

\section{Materials: bacteria and chemicals}

The target strains used in this study were: Listeria monocytogenes ATCC 35152 and Escherichia coli CIP 54127. Strains were maintained at $-80^{\circ} \mathrm{C}$ in Tryptone Soy Broth (TSB, Biokar Diagnistics, France) supplemented with 20\% (v:v) glycerol. Pectin was from (Cargill, 
Baupte, France). The degree of esterification was from $22 \%$ to $28 \%$ and degree of acetylation was from 20\% to 23\%. Maltodextrins DE 19 (dextrose equivalent value of 19) were obtained from (Roquette-freres SA, Lestrem, France). Benzalkonium chloride (BAC), analytical grade imidazole $\left(\mathrm{C}_{3} \mathrm{H}_{4} \mathrm{~N}_{2}\right)$, acetic acid, sodium hydroxide $(\mathrm{NaOH})$, hydrochloric acid $(\mathrm{HCl})$, and ethanol were purchased from (Sigma-Aldrich, St Quentin Fallavier, France). Distilled water was used for the preparation of all solutions.

\section{Stock solution preparation}

Imidazole-acetate buffer solutions $\left(5 \mathrm{~m} \mathrm{~mol} \mathrm{l}^{-1}\right)$ were prepared by dispersing weighed amounts of imidazole and acetic acid into distilled water. The stock solutions were prepared by dispersing BAC, pectin or maltodextrins powders into imidazole-acetate buffer stirring at room temperature until total hydration, and then the $\mathrm{pH}$ was adjusted to 7 by using $\mathrm{HCl}(0.1$ or 1.0 mol $\left.\mathrm{l}^{-1}\right)$ or $\mathrm{NaOH}\left(0.1\right.$ or $\left.1.0 \mathrm{~mol}^{-1}\right)$. The concentration of each stock solution (w:w) was: BAC $1 \%$, pectin $3 \%$, and maltodextrins $50 \%$. The $\mathrm{pH}$ of each solution was adjusted again to 7 before analysis.

\section{Complexes formation and spray-drying}

The suspensions of complexes were prepared by mixing the stock solutions and imidazoleacetate buffer to the desired concentration. Stock maltodextrins solutions were added to the prepared suspensions, to obtain a final concentration (w:w) of $20 \%$ maltodextrins DE 19 . Four complex pectin/BAC ratios of 1, 2, 2.5 and 3 were prepared. For complexed BACmicrocapsules study, only the ratio 3 was selected (20\% maltodextrins DE 19, 0.4\% BAC, 1.2\% pectin). The mixtures were stirred for $30 \mathrm{~min}$ and then spray-dried using a laboratory scale device equipped with a $0.5 \mathrm{~nm}$ nozzle atomizer (Mini Spray-Dryer Büchi B-290, Switzerland). The operational conditions of the drying process were as follow: feed flow rate: $0.51 \mathrm{~h}^{-1}$, inlet air temperature: $180 \pm 2^{\circ} \mathrm{C}$, and outlet air temperature: $80 \pm 5^{\circ} \mathrm{C}$. After spray-drying, the powders were collected in sealed containers and stored at $4^{\circ} \mathrm{C}$ until analysis. Reconstituted 
suspensions were prepared by dispersing weighted amounts (the same dry matter as before spray-drying) of spray-dried powders in imidazole-acetate buffer solutions (5 m mol l-1, $\mathrm{pH} 7)$ and stirring for $1 \mathrm{~h}$.

\section{Zeta potential measurement}

The electric charge of free molecules or complexes was determined using a Zetasizer Nano ZS90 (Malvern Instruments, Malvern, UK). The zeta-potential (ZP) of BAC and pectin was measured in imidazole-acetate buffer at different $\mathrm{pH}$ values. If necessary, the samples were diluted with corresponded $\mathrm{pH}$ imidazole-acetate buffer. Each test was repeated at least three times. The mean ZP values ( \pm SD: standard deviation) were obtained from the instrument.

\section{Particle size measurement}

Particle size distribution of complexes were assessed by a laser diffraction instrument (Mastersizer 3000, Malvern Instruments, Malvern, UK) with a value of 1.33 for water phase. To measure the particle size distribution of spray-dried microcapsules, the powder was slowly added into the measurement chamber containing ethanol (refractive index: 1.36) to avoid the dissolution of maltodextrins during the measurement. The spray-dried powders were continuously stirred throughout the measurement to ensure that the samples were homogeneous. The volume mean particle diameter $\left(\mathrm{D}_{43}\right)$ was calculated by the software from the three injections of three separate samples with five readings per sample.

\section{Moisture content}

The moisture content of spray-dried microcapsules was measured by drying in an oven at $160^{\circ} \mathrm{C}$ under air circulation for $24 \mathrm{~h}$. Spray-dried microcapsules $(\sim 1 \mathrm{~g})$ were placed in caps that were weighed before and after oven drying. Moisture content values were calculated as a fraction of the initial microcapsules weight lost during drying and were reported on a wet basis. 
L. monocytogenes and E. coli, were cultured overnight in TSB at $37^{\circ} \mathrm{C}$. Cells were pelleted by centrifugation $\left(5000 \mathrm{~g}, 5 \mathrm{~min}, 20^{\circ} \mathrm{C}\right)$ then washed with Potassium Phosphate Buffer (PPB; 100 $\mathrm{m} \mathrm{mol}^{-1}, \mathrm{pH}$ 7). Bacterial suspensions were diluted in TS broth to $10^{6} \mathrm{CFU} \mathrm{ml}^{-1}$. The Minimum inhibitory concentrations (MICs) of free-BAC, uncomplexed BAC-microcapsules (UBM) and complexed BAC-microcapsules (CBM) were determined by measuring kinetically, the development of turbidity by vertical photometry using a Bioscreen C (Labsystems, Helsinki, Finland), (Khelissa et al. 2018). Briefly, $100 \mu \mathrm{l}$ of bacterial suspension were added to the plate wells containing serial 2-fold dilutions from microcapsules or free BAC stock solution prepared

in TSB. A growth control (bacteria with microcapsule-free TSB), and a sterility control (with only microcapsule-free TSB) were added to each plate. Plates were incubated at $37^{\circ} \mathrm{C}$ under continuous shaking in the Bioscreen $\mathrm{C}$ which measured the optic density (OD) at $600 \mathrm{~nm}$ every $2 \mathrm{~h}$ during $24 \mathrm{~h}$. The MIC was defined as the lowest concentration preventing the bacterial growth, as measured by optical density. The experiment was repeated three times and mean OD $600 \mathrm{~nm}$ values were plotted versus time.

\section{Biofilm installation and disinfection assay}

All bacterial strains were precultured in TSB $(5 \mathrm{ml})$ for $24 \mathrm{~h}$ at $37^{\circ} \mathrm{C}$. Cultures were prepared by inoculating $50 \mathrm{ml}$ of TSB with $10^{4} \mathrm{CFU} \mathrm{m}{ }^{-1}$ from the preculture and incubated at $37^{\circ} \mathrm{C}$ overnight. Cells were and harvested by centrifugation $\left(5000 \mathrm{~g}, 5 \mathrm{~min}, 20^{\circ} \mathrm{C}\right)$ and washed twice with PPB. Bacterial suspensions were adjusted to $10^{8} \mathrm{CFU} \mathrm{m} \mathrm{m}^{-1}$ in PPB (OD $600 \mathrm{~nm} 0.110 \pm$ 0.005). Stainless steel slides $(50 \times 25 \mathrm{~mm})$ were covered with $3 \mathrm{ml}$ of the cell suspension adjusted to $10^{7} \mathrm{CFU} \mathrm{ml} \mathrm{m}^{-1}$ and allowed to stand at $20^{\circ} \mathrm{C}$ for $1 \mathrm{~h}$. Afterwards, slides were rinsed in PPB, to remove loosely attached cells. Each slide was covered with $3 \mathrm{ml}$ of TSB and incubated statically at $37^{\circ} \mathrm{C}$ for $24 \mathrm{~h}$. After $24 \mathrm{~h}$ of incubation, slides covered with biofilm were rinsed with PPB then placed horizontally in $20 \mathrm{ml}$ of the tested solution (at the MIC) and incubated for $10 \mathrm{~min}$. Afterwards, slides were withdrawn from the tested solution and immersed 
in $20 \mathrm{ml}$ of neutralizing solution (Toté et al. 2010) containing $1 \mathrm{~g}$ of $1 \mathrm{~mm}$ diameter glass beads in $100 \mathrm{ml}$ sterile pot to stop the antibacterial action. In order to detach the biofilm cells were from the stainless steel surface, pots were vortexed for $30 \mathrm{~s}$ followed by a sonication for $5 \mathrm{~min}$ $\left(37 \mathrm{kHz}, 20^{\circ} \mathrm{C}\right)($ Elmasonic S60H, Elma, Germany). Thereafter, pots were vortexed again for $30 \mathrm{~s}$ and serial dilutions were realized in TS. Samples of $100 \mu \mathrm{l}$ were spread onto TSA plates and incubated at $37^{\circ} \mathrm{C}$ for $24 \mathrm{~h}$. The number of viable and culturable cells was counted on plates and results were expressed in $\log \mathrm{CFU} \mathrm{cm}^{-2}$. For the control assays, the disinfectant solution was replaced by the TS. The cell viability percentage in treated biofilms was determined after staining with the LIVE/DEAD® BacLight Bacterial Viability kit (Invitrogen Molecular Probes, USA). Briefly, $10^{7} \mathrm{CFU} \mathrm{m}{ }^{-1}$ of detached cells were filtered through a $0.2 \mu \mathrm{m}$-pore-size black polycarbonate filters (Millipore, France) and stained for $10 \mathrm{~min}$ in the dark. Stained cells were washed once with $1 \mathrm{ml}$ of distillated water, and filters were air dried in the dark then observed under epifluorescence microscopic (Olympus BX43, Germany) for enumeration. The green cells (viable) and red ones (dead) were counted over 50 microscopic fields. The percentage of viable cells was calculated as follows: (Number of green cells x 100) / total number of both red and cells. Results represent the average of three independent experiments and in each case, two slides were used.

\section{Scanning electron microscopy (SEM)}

The morphology of biofilm bacterial cells treated for 10 min with free BAC or CBM at MICs was assessed by SEM and compared to negative control where cells were treated with Tryptone Salt (TS). Biofilm treatment cells were recovered according to Abdallah et al., (2014) and diluted (10-fold) Tryptone Salt (TS). Samples of $1 \mathrm{~mL}$ volume from the diluted biofilm cell suspensions were filtered through a $0.2-\mu \mathrm{m}$-pore-size polycarbonate membrane filter (Schleicher \& Schuell, Dassel, Germany) then fixed overnight with 2\% glutaraldehyde, cacodylate buffer $0.1 \mathrm{~mol} \mathrm{l}^{-1}, \mathrm{pH} 7$, at $4^{\circ} \mathrm{C}$. Fixed cell samples were dehydrated in an ascending 
ethanol series $(50 \%, 70 \%, 95 \%$, and $100 \%(\times 2)(\mathrm{v}: \mathrm{v})$ ethanol), for $10 \mathrm{~min}$ at each concentration and dried. Fixed bacterial samples were carbon coated and examined at an accelerating voltage of $3 \mathrm{kV}$.

\section{Epifluorescence microscopy analysis}

Biofilms were treated with free and encapsulated BAC and for the control biofilm were treated with TS. Biofilms were stained with LIVE/DEAD BacLight kit (Invitrogen Molecular Probes, USA), according to the manufacturer instruction for $15 \mathrm{~min}$. Biofilms were washed by genteelly dipping the stainless steel coupons in distillated water, air dried in the dark then observed under epifluorescence microscopic (Olympus BX43, Germany). The green cells were considered viable and red ones were defined as non-viable.

\section{Cytotoxicity assay}

The HeLa cell line derived from cervical carcinoma from a 31 year old female (ATCC® CCL$2^{\mathrm{TM}}$, ECACC, Sigma Aldrich, Saint-Quentin Fallavier, France) were cultured and maintained in Dulbecco's Modified Eagle's medium (DMEM, Gibco®) supplemented with $10 \%$ fetal bovine serum (FBS, Gibco $®)$ and $1 \%$ penicillin-streptomycin (Gibco®) in a humidified incubator at $37{ }^{\circ} \mathrm{C}$ and $5 \% \mathrm{CO}_{2}$. Cells were seeded at a density of $10^{4}$ cells per well in a 96-well plate and grown for $24 \mathrm{~h}$ before assay. The culture medium was replaced with a fresh medium that contains the compounds from 12.5 to $400 \mu \mathrm{g} \mathrm{ml}^{-1}$. After $24 \mathrm{~h}$, the old medium was removed and cells were washed with PBS. The cell viability was evaluated using resazurin cell viability method. Briefly, $100 \mu \mathrm{l}$ of the resazurin solution $\left(11 \mu \mathrm{g} \mathrm{ml}^{-1}\right)$ in complete medium were added to each well and the plate was incubated for $4 \mathrm{~h}$ in the humidified incubator. The fluorescence emission of each well was measured at $593 \mathrm{~nm}$ (20-nm bandwidth) with an excitation at 554 nm (18-nm bandwidth) using a Cytation ${ }^{\mathrm{TM}} 5$ Cell Imaging Multi-Mode Reader (BioTek Instruments SAS, France). Each condition was replicated three times and the mean fluorescence value of non-exposed cells (treated with TSB) was taken as $100 \%$ cellular viability. 


\section{Statistical analysis}

All experiments were carried out at least three times. Statistical study was performed with IBM SPSS 19 statistics software following the one-way ANOVA. Results are considered significantly different when $P<0.05$.

\section{Results}

BAC-LM pectin interactions and properties of the formed complexes

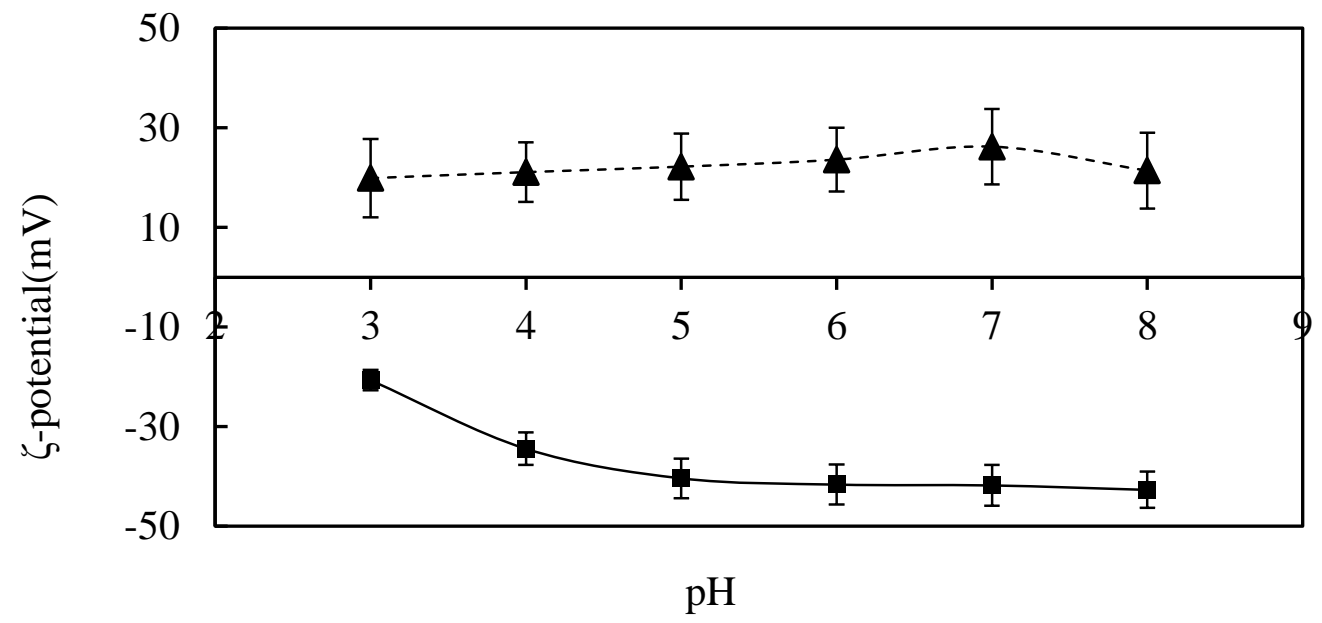

\section{Figure 1}

To choose optimum $\mathrm{pH}$ for the complexation, the zeta-potential (ZP) of $\mathrm{BAC}$ and pectin as function of $\mathrm{pH}$ was measured as shown in Figure 1. At the $\mathrm{pH}$ range from 3 to 8 , pectin was negatively charged. In detail, the absolute value of ZP for pectin obviously increased with increasing the $\mathrm{pH}$ from 3 to 5 , which was due to the deprotonation of carboxyl groups. With continual increase of $\mathrm{pH}$ over 5, the changes in $\mathrm{ZP}$ value became unobvious, which indicated the end of deprotonation of carboxyl groups. The zeta-potential of BAC was overall stable at around $+20 \mathrm{mV}$ whatever the $\mathrm{pH}$ value. At pectin/BAC mass ratio 1.5, the complexes of BAC and pectin became electrical neutral at $\mathrm{pH} 7$ (Figure 2). 


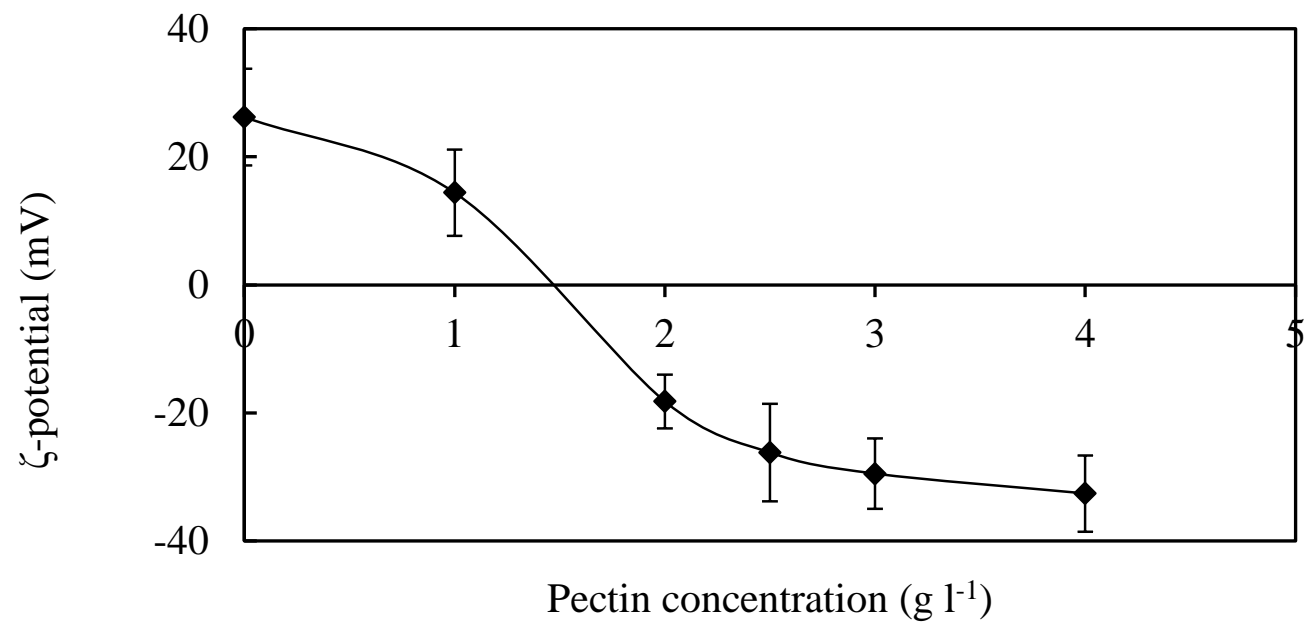

Figure 2

The $\mathrm{ZP}$ of the complexes reached a plateau after the pectin/BAC mass ratio reached 3, which could be indicated that positively charged BAC groups were fully occupied by pectin (Figure

2). Therefore, this ratio was chosen for the following experiments as it allowed to have small complexes having a compact structure (Figure 3). Nevertheless, at ratio 4, the high pectin amount resulted in the dissociation of pectin/BAC complexes. This could be due to the bridging of BAC molecules which significantly $(P<0.05)$ increased the size of complexes (Figure 3$)$.

For high concentrations of pectin, the complexes can dissociate and a single molecule of BAC could bound to several chains of pectin which increases the apparent size of the complexes.

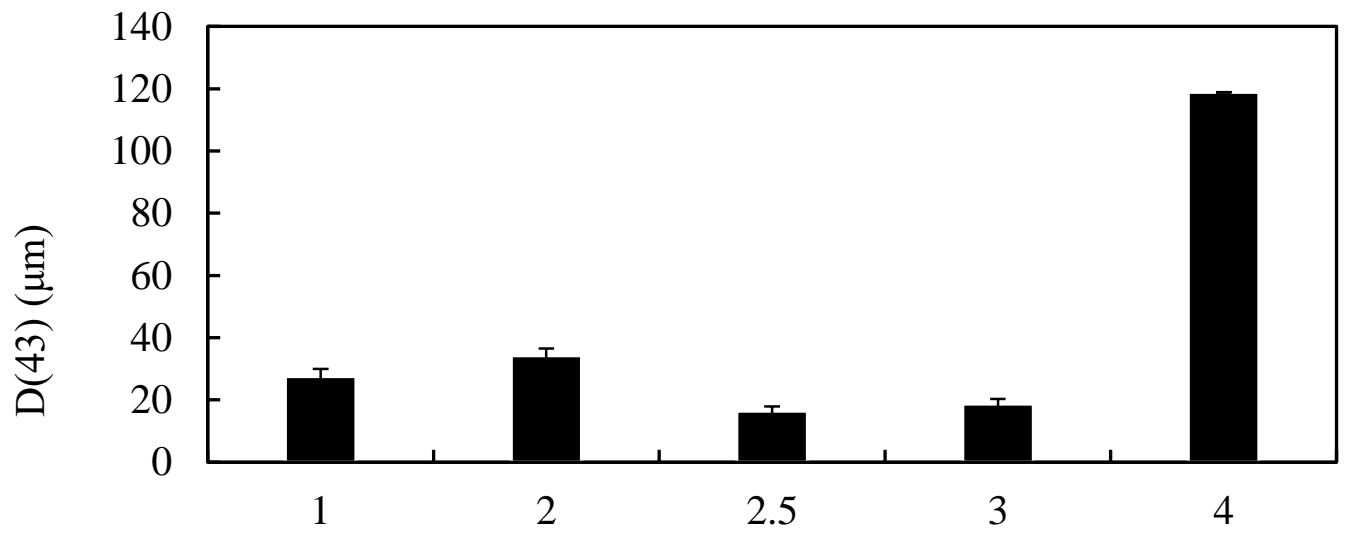

Pectin/BAC ratio 


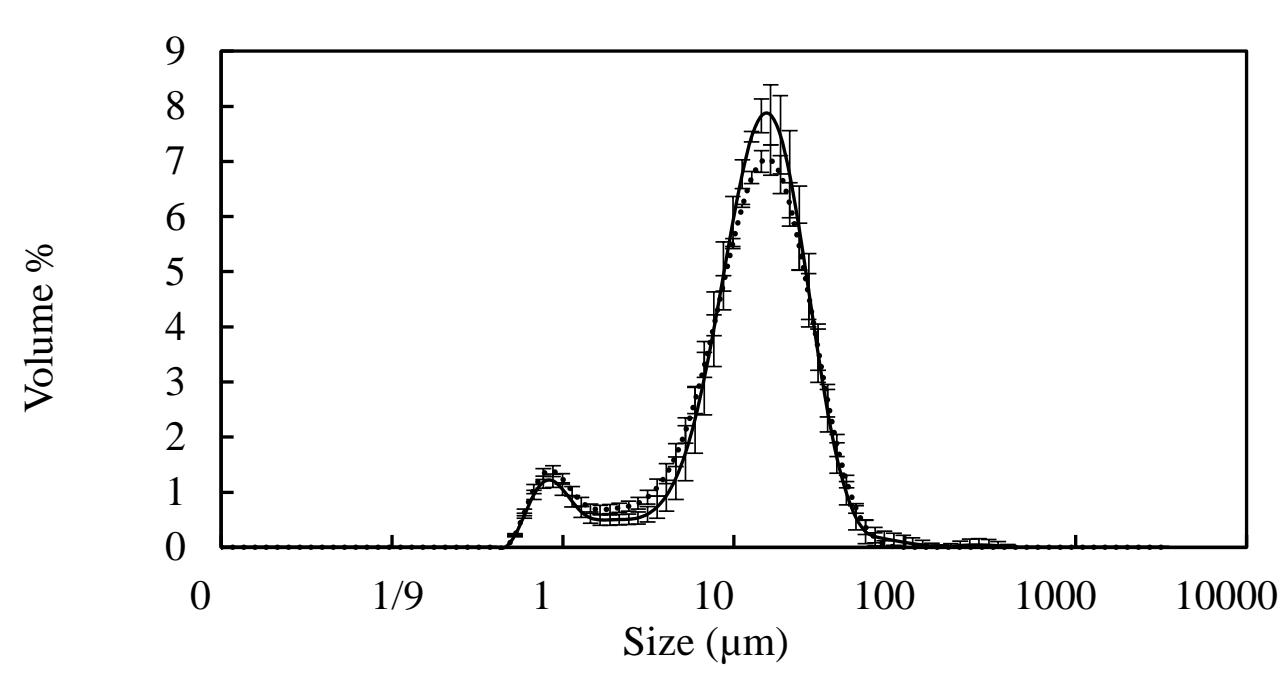

a

$\mathrm{b}$

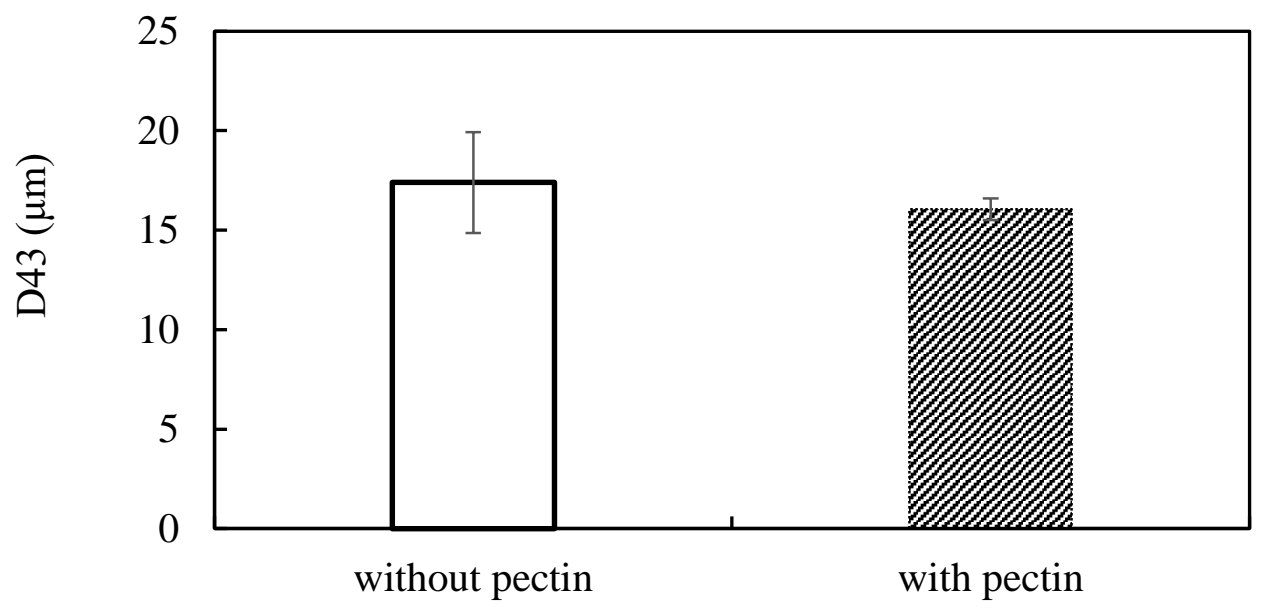

Figure 4

The spray-dried BAC microcapsules were white color with low moisture content of $3.70 \%$ and

$5.15 \%$ for UBM and CBM, respectively. Pectin is a polyanionic biopolymer which has a high affinity with water molecules, which explains the highest water content for CBM. On the other hand, for the 2 types of capsules, these water contents should make it possible to have good storage capacities. The particle size of spray-dried microcapsules with and without pectin showed no significant difference $(P>0.05)$ in their particle size distribution (Figure 4 a). For 
details, the mean diameters $\left(\mathrm{D}_{43}\right)$ were ranged between $17.3 \mu \mathrm{m}$ for spray-dried BAC without pectin and $16 \mu \mathrm{m}$ for spray-dried BAC with pectin microcapsules (Figure $4 \mathrm{~b}$ ). These particle distribution properties should make it possible to have fluid powders with good properties of use whatever the type of microcapsules.

Assessment of bacterial susceptibility to free and microencapsulated BAC

Table 1. Minimal inhibitory concentration (in $\mathrm{mg}^{-1}$ ) of free and encapsulated BAC against $E$. coli and L. monocytogenes.

\begin{tabular}{lccc} 
Bacterial strains & free BAC & CBM & UBM \\
\hline E. coli & 12.5 & 3.12 & 6.25 \\
\hline L. monocytogenes & 6.25 & 1.56 & 3.12
\end{tabular}

Abbreviations: BAC, benzalkonium chloride; CBM: complexed BAC-microcapsules; UBM: uncomplexed BAC-microcapsules.

The MIC of CBM and UBM microcapsules were determined and compared to those of free BAC against L. monocytogenes ATCC 35152 and E. coli CIP 54127. The obtained results are shown in Table 1 . The MICs of the encapsulated BAC were significantly $(P<0.05)$ lower than those of free BAC against all studied strains. In addition, the MICs of CBM were 2-fold $(P<$ 0.05) lower than those of UBM whatever the studied strain (Table 1). L. monocytogenes was 2fold more susceptible to all studied BAC forms than E. coli (Table 1).

\section{Antibiofilm assays}




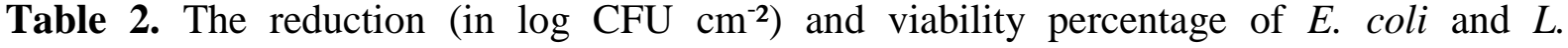
monocytogenes biofilm biomass after treatments with free or microencapsulated BAC.

\begin{tabular}{lcccccc}
\hline Bacteria & \multicolumn{2}{l}{ Viable cells \% } & \multicolumn{3}{c}{ Biomass log reduction } \\
\hline & BAC & CBM & UBM & BAC & CBM & UBM \\
\hline E. coli & $69 \pm 2$ & $57 \pm 3$ & $65 \pm 2$ & $1.8 \pm 0.2$ & $3.1 \pm 0.1$ & $2.1 \pm 0.1$ \\
L. monocytogenes & $52 \pm 3$ & $37 \pm 2$ & $48 \pm 3$ & $2.5 \pm 0.3$ & $3.6 \pm 0.2$ & $2.3 \pm 0.1$
\end{tabular}

Abbreviations: BAC: benzalkonium chloride; CBM: complexed BAC-microcapsules; UBM: uncomplexed BAC-microcapsules. Data presented as means $( \pm \mathrm{SD})$ of three independent repeats.

The antibiofilm efficacy of CBM and UBM used at their MICs was investigated on $L$. monocytogenes and E. coli biofilms and compared to that of free BAC, respectively. The results obtained were expressed as $\log \mathrm{CFU} \mathrm{\textrm {cm } ^ { - 2 }}$ reductions in treated biofilms, compared to untreated controls (Table 2). The treatment with free BAC resulted in log reduction of the initial biomasses of E. coli and L. monocytogenes biofilms by 1.8 and $2.5 \log \mathrm{CFU} \mathrm{cm} \mathrm{cm}^{-2}(P<0.05)$, respectively (Table 2). Similar results were observed after treatment with UBM (Table 2). The treatment with CBM resulted in a significant log reduction of $c a 3.1$ and $3.6 \log \mathrm{CFU} \mathrm{cm} \mathrm{cm}^{-2}(P$ $<0.05$ ), for E. coli and L. monocytogenes, respectively. CBM showed higher antibiofilm effect as compared to $\operatorname{UBM}(P<0.05)$. Furthermore, the percentage of viable cells after staining with the SYTO9 and propidium iodide (PI), showed that untreated E. coli and L. monocytogenes biofilms were composed mainly of viable cells (respectively of $c a 93$ and 96\%, data not shown). The results presented in Table 2 also suggest that the treatment with free BAC reduced the viability of $E$. coli and L. monocytogenes biofilms to 69 and 52\% respectively $(P<0.05)$. After treatment with CBM and UBM the remaining E. coli viable cells percentage was of $c a 57$ and $65 \%$ respectively $(P<0.05)$. The viability percentages of $L$. monocytogenes after treatment 

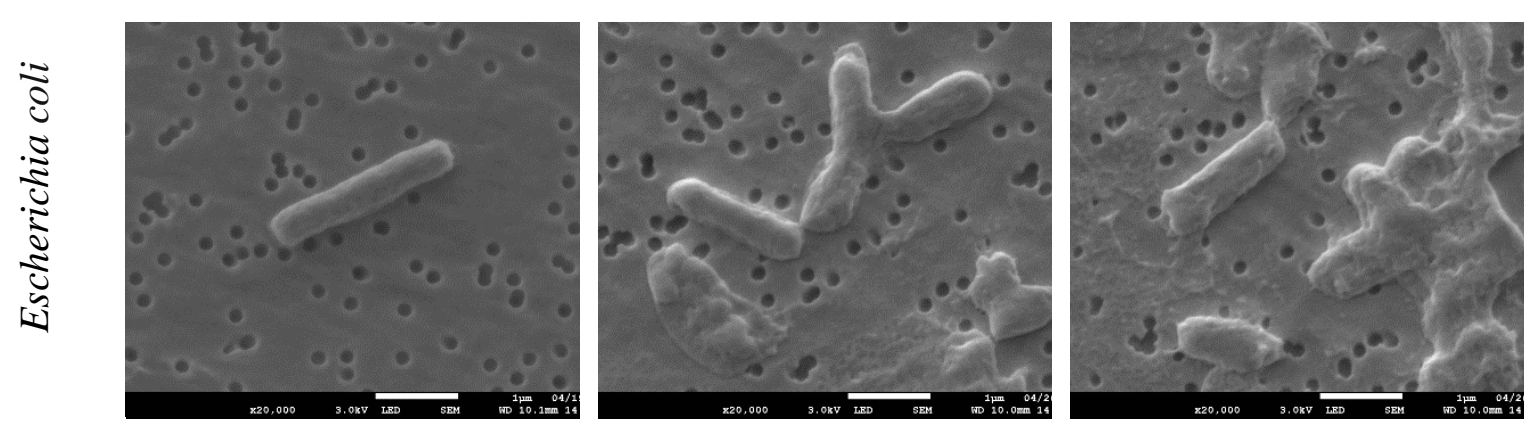

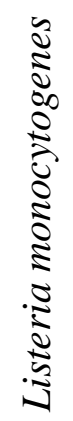
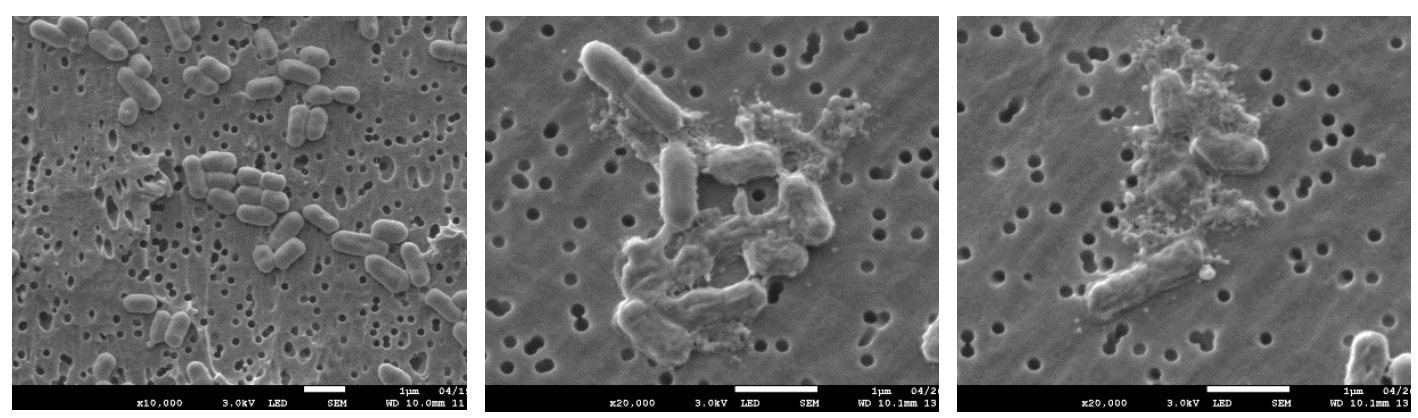

312

\section{Figure 5}

To investigate the morphological modifications of E. coli and L. monocytogenes biofilm cells analyzed by SEM. As the effect of both free BAC and UBM on treated cells morphology was similar, UBM-treated cells micrographs were not shown (Figure 5). The negative control (cells 
treated with TS) showed intact cells which exhibited a normal and smooth lining (Figure 5).

320 However, whatever the studied bacteria strain, the exposure to both free-BAC and CBM 321 solutions (concentration adjusted to the MIC) for $15 \mathrm{~min}$ led to significant structural collapse

322 (Figure 5). Cells seemed irreversibly lysed, deformed and showed holes in their cell walls 323 (Figure 5).

Control
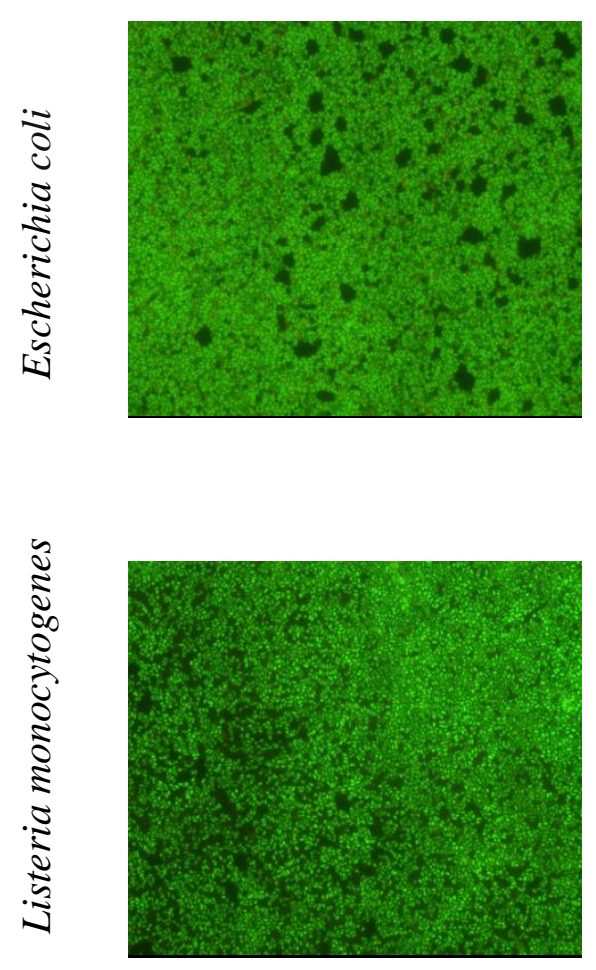

free-BAC
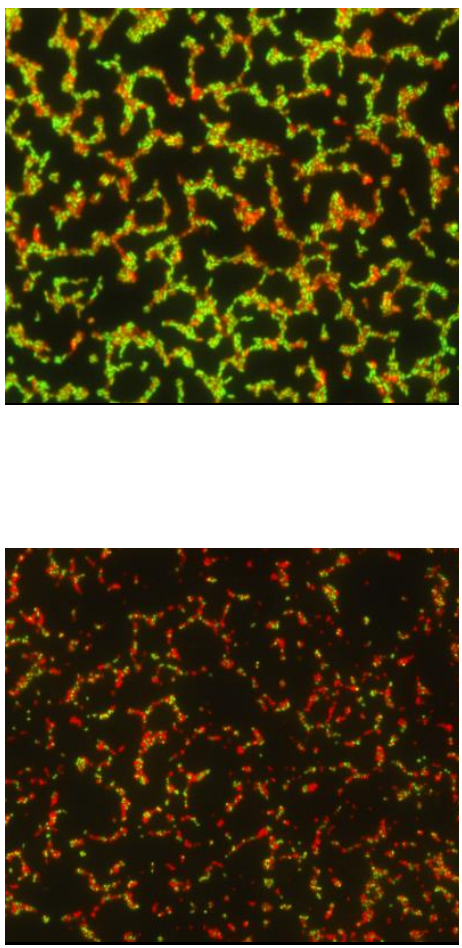

CMB
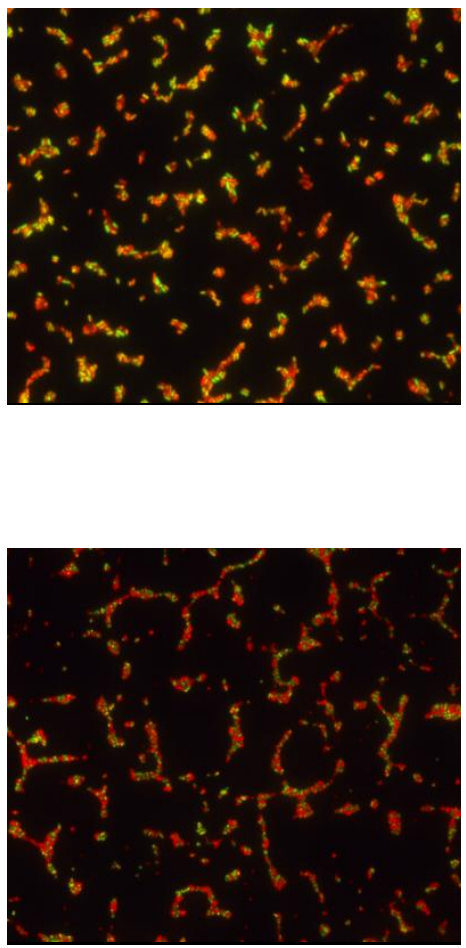

\section{Figure 6}

329 Figure 6 showed epifluorescence microscopy images of $24 \mathrm{~h} \mathrm{E}$. coli and L. monocytogenes biofilms stained with SYTO9 and PI after treatment with free and encapsulated BAC. The control (biofilm treated with TS) showed a thick and covering viable biomass mainly stained with SYTO9. The treatment with BAC and CBM resulted in a significant removal of biofilm 
333

334

biomass from the SS coupon. Furthermore, the density of remaining biofilm cells stained with PI after antibacterial treatment increased significantly. The results demonstrated a higher level of cell dispersion after treatment with CBM as a very thin cell layer mostly stained with PI was observed (Figure 6). According to our results, there was a correlation between the cellular membrane integrity and the remaining biofilm cell biomass after treatment with both free BAC and CBM which highlights the possible modes of action of these antimicrobials.

Cytotoxicity of free and microencapsulated BAC

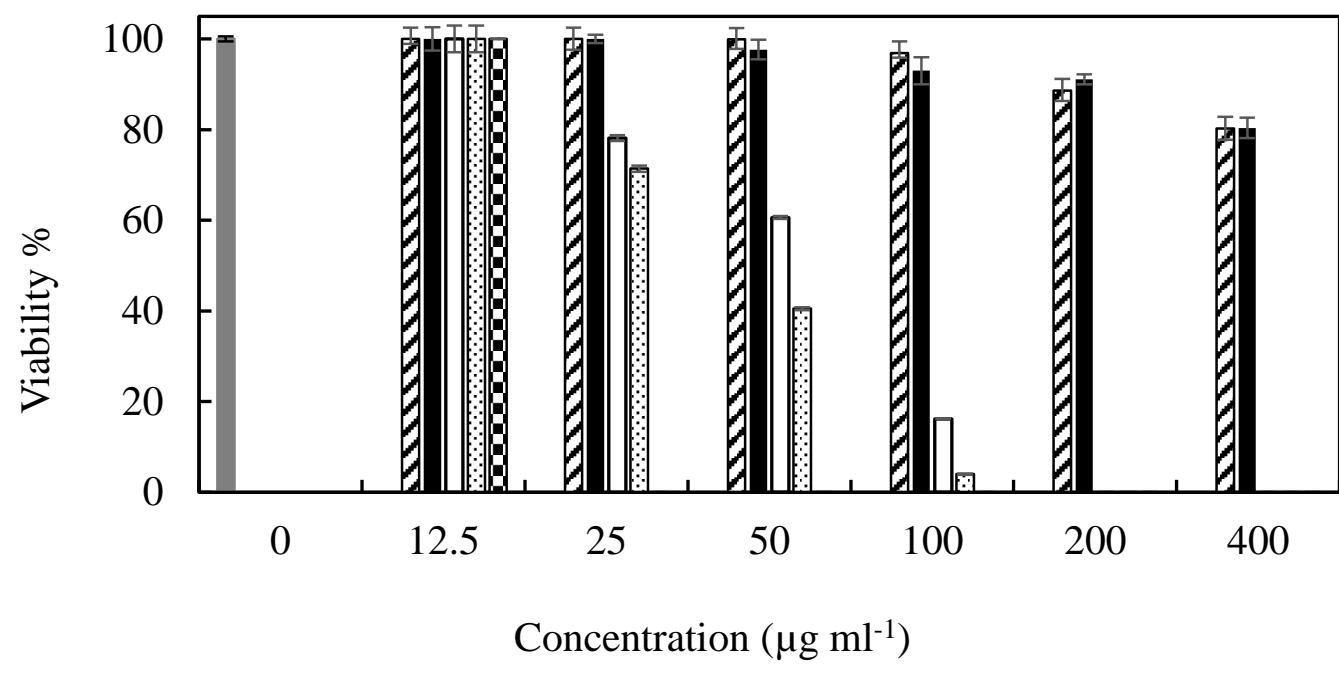

Figure 7

The viability of $\mathrm{HeLa}$ cells was assessed after $24 \mathrm{~h}$ contact with free and micro-encapsulated BAC concentrations ranging from 12.5 to $400 \mu \mathrm{g} \mathrm{ml}^{-1}$ (Figure 7). The TSB was used as a negative control. Two additional controls consisting of microcapsules formulated without BAC (empty UBM and CBM). Figure 7 showed that TSB had no negative effect on HeLa cells viability. When used at concentrations between 12.5 and $100 \mu \mathrm{g} \mathrm{ml}^{-1}$, both empty UBM and CBM had no cytotoxic effect on HeLa cells which showed a viability percentage of $c a 100 \%$ after being in contact with empty microcapsules for $24 \mathrm{~h}$. However, at concentrations of 200 and $400 \mu \mathrm{g} \mathrm{ml}^{-1}$ the viability of HeLa cells was reduced by 10 and $20 \%$ respectively, whatever 
the studied empty microcapsules (Figure 7). Contact with BAC at $12.5 \mu \mathrm{g} \mathrm{ml}^{-1}$ was not toxic to HeLa cells which remained $100 \%$ viable (Figure 7). Our findings, underlined that exposure to BAC concentrations greater than, or equal to $25 \mu \mathrm{g} \mathrm{ml}^{-1}$ was significantly cytotoxic $(P<0.05)$ and led to $100 \%$ HeLa cells viability reduction (Figure 7). Furthermore, CBM and UBM demonstrated reduced cytotoxicity towards HeLa cell, with a minimum needed concentration of $200 \mu \mathrm{ml}^{-1}$ to completely kill the HeLa cells. Nevertheless, CBM were significantly more cytotoxic then UBM $(P<0.05)$ (Figure 7). These results confirm the ability of microencapsulation to enhance the antibacterial effect of BAC while reducing its health hazard even at doses that would otherwise be completely toxic.

\section{Discussion}

BAC is different from biomacromolecules like pectin having a complex molecular structure. The antimicrobial used in this study has a simpler molecular structure which consists of quaternary cationic nitrogen atom linked with a benzyl group, two methyl groups and an alkyl chain (C16). The molecular structure of BAC could induce, in aqueous phase, the formation of micelles by inside hydrophobic long alkyl chains that can be surrounded by positively charged nitrogen atoms. The structure of BAC micelles with positively charged nitrogen atoms on the surface would not change with the change of $\mathrm{pH}$ (Ilari et al., 2014). Considering that pectin and BAC carried opposite charges at the tested $\mathrm{pH}$ range, the most common $\mathrm{pH}$ for several applications, $\mathrm{pH}$ 7, was chosen for the formation of electrostatic complexes in this study. Pectin is net negatively charged at $\mathrm{pH} 7$, and can combine sufficiently with positively charged BAC via electrostatic attractive interactions. Therefore, the ZP of pectin/BAC complexes gradually decreased with increasing the amount of added pectin (Figure 2).

Furthermore, our results showed that CBM and UBM microcapsules had low moisture content witch was slightly higher for those containing pectin. This could be due to the water holding capacity of pectin. In this context, Botrel et al. (2017) reported that the differences in the 
moisture content presented between particles were due to the affinities of the materials to water and moisture diffusivities through the wall matrix. This moisture content is fitted in the ideal moisture content range as 3-5\% (Crouter and Briens 2014).

The size distribution of spray-dried microcapsules with and without pectin showed no significant difference $(P>0.05)$. This result was expected since the same drying conditions were used for all the feed solutions (temperature, pulverization pressure). However, Sansone et al. (2011) have shown that the presence of pectin affects the maltodextrin/pectin particle size significantly. To assess the susceptibility of L. monocytogenes and E. coli to the different form of BAC, the MIC of CBM and UBM microcapsules were determined and compared to those of free BAC. Our results showed that the encapsulation of BAC reduced the its MIC significantly $(P<0.05)$. In addition, the MICs of CBM were 2 -fold $(P<0.05)$ lower than those of UBM whatever the studied strain. We demonstrated that treatment with CBM used at the MIC reduced significantly the viability and cultivability of L. monocytogenes and E. coli biofilm cells. The antibiofilm effect of CMB was significantly greater than those of free BAC and UBM whatever the studied strain. These results are consistent with those obtained by Wang et al. (2019) for citral microcapsules which showed an increase of the antibacterial effect of this essential oil against several food pathogens when pectin was added to emulsified citral. This could be due to the presence of a proper concentration of BAC in close of bacterial cells that could result from a controlled release of BAC encapsulated in presence of pectin.

It has been reported that the antibacterial activity of many antimicrobial agents including BAC results in the disruption of the cell membrane integrity through the insertion of the antimicrobial agent in the cell membrane, leading to the collapse of the membrane and to the leakage of cytoplasmic pool or penetration of the compound into the cell, affecting internal homeostasis (McLandsborough et al. 2006; Khelissa et al. 2018, 2019). Thus, we observed the morphology of bacterial cells after antibacterial treatment with SEM. SEM micrographs showed the 
structural collapse and the irreversible lysis of cell walls. These observations are consistent with our previously reported studies regarding the damage made by BAC to bacterial cells membrane integrity (Khelissa et al. 2018, 2019). Like any other QAC, BAC is toxic for mammalian cells. Our findings, underlined that exposure to BAC concentrations greater than, or equal to $25 \mu \mathrm{g}$ $\mathrm{ml}^{-1}$ killed HeLa cells up to $100 \%$. Our results, are consistent with those reported by Deutschle et al. (2006), who reported that BAC used at low concentration $(0.01 \%)$ nearly kill all human respiratory epithelial BEAS-2B cell line after $2 \mathrm{~h}$ of exposure. These results highlighted the health and environmental hazards associated to the BAC even at very low concentrations. In addition, cytotoxicity assays showed apoptotic effects for lower concentrations and necrotic effects for higher concentrations of BAC (Deutschle et al. 2006).

Exposure of HeLa cells to high concentrations of empty microcapsules (formulated without BAC) resulted in up to $20 \%$ reduction of initial viability. This could be explained by the highdose-toxicity effect over $200 \mu \mathrm{g} \mathrm{m} \mathrm{m}^{-1}$. It has been demonstrated that pectin-derived acidic oligosaccharides in mammalian assays were classified as cytotoxic only at highly concentrations (Garthoff et al. 2010; Fiume et al. 2016). Our results showed that the microencapsulation of BAC significantly reduced its cytotoxicity toward HeLa cells. The significant reduction in BAC toxicity is an important step in advancing the developed UBM and CBM towards industrial application.

In summary, BAC was successfully encapsulated by electrostatic complexation with pectin using spray-drying technique. We studied the effect of complexation and spray-drying on the antimicrobial action of BAC. The results showed that the complexation of BAC with pectin would control its release kinetics from microcapsules, and therefore improve its effectiveness against bacteria contaminating food. The increase of the pectin amount influenced the particle size of BAC/pectin complexes before spray-drying. Microbiological tests demonstrated that complexed BAC microcapsules (CBM) had the highest antimicrobial activity than 
uncomplexed ones (UBM). Exposure of E. coli and L. monocytogenes biofilms MICs of free and microencapsulated BAC resulted in the modification of overall biofilm cell viability, cell morphology, and cell biomass dispersal. In addition, both CBM and UBM were more efficient than free BAC when they are applied against several food pathogen biofilms. The application of such a BAC microcapsule-based delivery system can improve the surface disinfection procedures and reduce the generated chemical wastes that seems to be a good strategy to maintain hygiene in concerned sectors.

\section{Acknowledgments}

This work was carried out within the framework of ALIBIOTECH program (Agroalimentaire et Biotechnologie). The authors also thank the Haut de France region and FEDER (Fonds Européen de Développement Régional) for their financial support.

\section{Conflict of Interest}

There is no conflict of interest

\section{References}

Abdallah, M., Chataigne, G., Ferreira-Theret, P., Benoliel, C., Drider, D., Dhulster, P. and Chihib, N.-E. (2014) Effect of growth temperature, surface type and incubation time on the resistance of Staphylococcus aureus biofilms to disinfectants. Appl Microbiol Biotechnol. 98, 2597-2607.

Abrahão, F.R., Rocha, L.C.R., Santos, T.A., Carmo, E.L. do, Pereira, L.A.S., Borges, S.V., Pereira, R.G.F.A. and Botrel, D.A. (2019) Microencapsulation of bioactive compounds from espresso spent coffee by spray drying. $L W T$. 103, 116-124.

Ben Amara, C., Eghbal, N., Degraeve, P. and Gharsallaoui, A. (2016) Using complex coacervation for lysozyme encapsulation by spray-drying. J Food Eng. 183, 50-57. 
Ben Amara, C., Kim, L., Oulahal, N., Degraeve, P. and Gharsallaoui, A. (2017) Using complexation for the microencapsulation of nisin in biopolymer matrices by spraydrying. Food Chem. 236, 32-40.

Botrel, D.A., Borges, S.V., Yoshida, M.I., Feitosa, J.P. de A., Fernandes, R.V. de B., de Souza, H.J.B. and de Paula, R.C.M. (2017) Properties of spray-dried fish oil with different carbohydrates as carriers. J Food Sci Technol. 54, 4181-4188.

Chen, M., Zhang, X., Wang, Z., Liu, M., Wang, L. and Wu, Z. (2018) Impacts of quaternary ammonium compounds on membrane bioreactor performance: Acute and chronic responses of microorganisms. Water Res. 134, 153-161.

Crouter, A. and Briens, L. (2014) The effect of moisture on the flowability of pharmaceutical excipients. AAPS PharmSciTech. 15, 65-74.

Deutschle, T., Porkert, U., Reiter, R., Keck, T. and Riechelmann, H. (2006) In vitro genotoxicity and cytotoxicity of benzalkonium chloride. Toxicol in Vitro. 20, 14721477.

Elersek, T., Zenko, M. and Filipic, M. (2018) Ecotoxicity of disinfectant benzalkonium chloride and its mixture with antineoplastic drug 5-fluorouracil towards alga Pseudokirchneriella subcapitata. PeerJ. 6, e4986.

Ferk, F., Misik, M., Hoelzl, C., Uhl, M., Fuerhacker, M., Grillitsch, B., Parzefall, W., Nersesyan, A., Micieta, K., Grummt, T., Ehrlich, V. and Knasmuller, S. (2007) Benzalkonium chloride (BAC) and dimethyldioctadecyl-ammonium bromide (DDAB), two common quaternary ammonium compounds, cause genotoxic effects in mammalian and plant cells at environmentally relevant concentrations. Mutagenesis. 22, 363-370. 
Fiume, M.M., Heldreth, B., Bergfeld, W.F., Belsito, D.V., Hill, R.A., Klaassen, C.D., Liebler, D.C., Marks, J.G.J., Shank, R.C., Slaga, T.J., Snyder, P.W. and Andersen, F.A. (2016) Safety assessment of microbial polysaccharide gums as used in cosmetics. Int J Toxicol. 35, 5S-49S.

Garthoff, J.A., Heemskerk, S., Hempenius, R.A., Lina, B.A.R., Krul, C.A.M., Koeman, Jan.H. and Speijers, G.J.A. (2010) Safety evaluation of pectin-derived acidic oligosaccharides (pAOS): Genotoxicity and sub-chronic studies. Regul Toxicol Pharmacol. 57, 31-42.

Ilari, R., Etcheverry, M., Zenobi, C. and Zanini, G. (2014) Effect of the surfactant benzalkonium chloride in the sorption of paraquat and cadmium on montmorillonite. IJENVH. 7, 70.

Kampf, G. (2018) Adaptive microbial response to low-level benzalkonium chloride exposure. J Hosp Infect. 100, e1-e22.

Khelissa, S.O., Abdallah, M., Jama, C. and Chihib, N.-E. (2019) Actively detached Pseudomonas aeruginosa biofilm cell susceptibility to benzalkonium chloride and associated resistance mechanism. Arch Microbiol. 201, 747-755.

Khelissa, S.O., Abdallah, M., Jama, C., Gharsallaoui, A. and Chihib, N.-E. (2018) Comparative study of growth temperature impact on the susceptibility of biofilm-detached and planktonic Staphylococcus aureus cells to benzalkonium chloride. Ann Microbiol.

Kim, M., Weigand, M.R., Oh, S., Hatt, J.K., Krishnan, R., Tezel, U., Pavlostathis, S.G. and Konstantinidis, K.T. (2018) Widely used benzalkonium chloride disinfectants can promote antibiotic resistance. Appl Environ Microbiol. 84, e01201-18.

McLandsborough, L., Rodriguez, A., Pérez-Conesa, D. and Weiss, J. (2006) Biofilms: at the interface between biophysics and microbiology. Food Biophys. 1, 94-114. 
Mulder, I., Siemens, J., Sentek, V., Amelung, W., Smalla, K. and Jechalke, S. (2018) Quaternary ammonium compounds in soil: implications for antibiotic resistance development. Rev Environ Sci Bio/Technol. 17, 159-185.

Phan, H.D. (2019) Decision of the board of appeal of the european chemicals agency. In The Timor-Leste/Australia Conciliation. pp.31-52. World Scientific.

Sansone, F., Mencherini, T., Picerno, P., d'Amore, M., Aquino, R.P. and Lauro, M.R. (2011) Maltodextrin/pectin microparticles by spray drying as carrier for nutraceutical extracts. J Food Eng. 105, 468-476.

Toté, K., Horemans, T., Vanden Berghe, D., Maes, L. and Cos, P. (2010) Inhibitory effect of biocides on the viable masses and matrices of Staphylococcus aureus and Pseudomonas aeruginosa biofilms. Appl Environ Microbiol. 76, 3135-3142.

Wang, J., Khelissa, S.O., Chihib, N.-E., Dumas, E. and Gharsallaoui, A. (2019) Effect of drying and interfacial membrane composition on the antimicrobial activity of emulsified citral. Food Chem. 298, 125079.

Zhang, C., Cui, F., Zeng, G., Jiang, M., Yang, Z., Yu, Z., Zhu, M. and Shen, L. (2015) Quaternary ammonium compounds (QACs): a review on occurrence, fate and toxicity in the environment. Sci Total Environ. 518-519, 352-362. 
516

517

518

519

520

521

522

523

524

525

526

527

528

529

530

531

532

533

534

535

536

537

538

\section{Figures Captions}

Figure 1. Zeta-potential of benzalkonium chloride (BAC) -- - -- and pectin $-\mathbf{-}-$ in imidazole acetate buffer at different $\mathrm{pH}$.

Figure 2. Zeta-potential of $\mathrm{BAC} /$ pectin complexes as a function of pectin concentration at $\mathrm{pH}$ 7 (the concentration of BAC is constant at $1 \mathrm{~g}^{-1}$ ).

Figure 3. Particle size distribution of BAC/pectin complexes as a function of pectin/BAC ratio.

Figure 4. Particle size distribution and corresponding average size of spray-dried microcapsules; (a) Particle size distribution of BAC spray-dried microcapsules formulated with pectin or without pectin —;

(b) corresponding average size of BAC spray-dried microcapsules formulated with pectin $\mathscr{W}$ or without pectin $\square$.

Figure 5. Scanning electron micrographs of Escherichia coli and Listeria monocytogenes, biofilm cells grown at $37^{\circ} \mathrm{C}$ for $24 \mathrm{~h}$, after treatment with free benzalkonium chloride (freeBAC) or pectin-complexed BAC-microcapsules $(\mathrm{CBM})$ at the minimum bactericidal concentration for $10 \mathrm{~min}$. The control represents cells treated with Tryptone Salt Buffer.

Figure 6. Fluorescence microscopy images of Escherichia coli and Listeria monocytogenes, biofilm cells grown at $37{ }^{\circ} \mathrm{C}$ for $24 \mathrm{~h}$ on the stainless steel after treatment with free benzalkonium chloride (free-BAC) or pectin-complexed BAC-microcapsules (CBM) at the minimum inhibitory concentration. Cells were visualized after staining with SYTO-9 (green fluorescence for living bacteria) and propidium iodide (red fluorescence for dead bacteria). The control represents cells treated with Tryptone Salt Buffer.

Figure 7. HeLa cells viability percentage after $24 \mathrm{~h}$ exposure to concentrations (between 12.5 and $400 \mu \mathrm{g} \mathrm{ml}^{-1}$ ) of free BAC $\mathbf{Q}$; pectin-complexed BAC-microcapsules (CBM) $\mathrm{O}$; Spray dried pectin microcapsules without BAC (empty CBM) $\square$; uncomplexed BAC-microcapsules 
539 (UBM) $\square$; Uncomplexed microcapsules formulated without BAC (empty UBM) $\boldsymbol{Z}$.The control 540 represents cells treated with Tryptone Soy Broth (TSB) 